\title{
Calcineurin Inhibitor Toxicity in Solid Organ Transplantation
}

\author{
Andrea Karolin $^{a} \quad$ Vera Genitsch ${ }^{b}$ Daniel Sidler ${ }^{a}$ \\ ${ }^{a}$ Department for Nephrology and Hypertension, University Hospital Insel Bern, Bern, Switzerland; b Institute for \\ Pathology, University of Bern, Bern, Switzerland
}

\begin{abstract}
Keywords
Calcineurin inhibitors - Cyclosporine A - Kidney disease .

Fibrosis · Arteriohyalinosis
\end{abstract}

\begin{abstract}
Calcineurin inhibitors (CNIs) have a substantial role in maintaining immunosuppression after solid organ transplantation (SOT). These drugs have a narrow therapeutic window, and individual doses and drug treatment monitoring are necessary. Still, a substantial proportion of patients suffer from short- or long-term calcineurin inhibitor toxicity (CNT), including kidney function impairment, hypertension, neurotoxicity, and metabolic disturbances. The authors discuss pathophysiology, clinical presentation, and histological features of CNT, with focus on renal manifestations. Furthermore, we elucidate recent and ongoing attempts to reduce the burden of CNT in SOT including CNI-sparing and CNI-free regimens.

(c) 2021 S. Karger AG, Basel
\end{abstract}

\section{Introduction}

\section{Clinical Evidence for Calcineurin Inhibitor Toxicity}

Solid organ transplantation (SOT) has rapidly evolved since the 1960s as the primary treatment for patients with advanced and end-stage renal, liver, heart, and lung diseases $[1,2]$. Early outcomes were complicated with acute rejection episodes and rapid deterioration of allograft function and subsequent loss [3]. With the introduction of individualized immunological matching at allocation [4] and the modern immunosuppressive regimens, allograft and patient outcome have substantially improved ever since. Calcineurin inhibitors (CNIs) including cyclosporine A (CsA) and tacrolimus (Tac) were approved as an immunosuppressive treatment in 1983 and 1999, respectively, by the US Food and Drug Administration [5, 6] and have substantially contributed to long-term control of antiallograft immunity. However, CNIs have a narrow therapeutic window and are responsible for substantial side effects, including nephrotoxicity, hypertension, neurotoxicity, tremor, and metabolic disturbances [7]. Indeed, CNIs may induce acute and dose-dependent renal dysfunction with the histological correlate of tubular vacuolization and epithelial necrosis, rarely accompanied with thrombotic microangiopathy (TMA). Alternatively, CNIs induce a rather dose-independent chronic renal toxicity with progressive athero- and arteriohyalionosis and interstitial fibrosis and tubular atrophy (IFTA) [8]. In a landmark article, Nankivell demonstrated that histological features of chronic calcineurin inhibitor toxicity $(\mathrm{CNT})$ are present in virtually all per-protocol biopsies in kidney allografts 10 years after transplantation, and advanced lesions are associated with inferior renal function and premature graft failure [9].

CNT not only affects kidney transplanted patients but also patients under long-term CNI treatment due to non- karger@karger.com www.karger.com/pha (c) 2021 S. Karger AG, Basel

Karger"
Correspondence to:

Daniel Sidler, daniel.sidler@insel.ch 
renal SOT or autoimmune diseases. Ojo et al. [10] showed that chronic renal disease also occurs with a 5 -year cumulative incidence in nonrenal SOT with $10.9 \%$ after a heart transplantation and $18.1 \%$ after liver transplantation. Nonrenal transplant recipients showing chronic renal failure under CNI treatment also have a 4 times higher risk of death [10]. The progressive estimated glomerular filtration rate (eGFR) decline is at least partially caused by $\mathrm{CNI}$ treatment, since prospective trials with CNI-avoiding regimens show superior long-term kidney function in patients randomized to the CNI-free arm (see below) [11].

\section{CNI-Sparing and CNI-Avoiding Treatment Options in SOT}

For many years, Tac was claimed to induce less nephrotoxicity, mainly due to its higher potency and less likely off-target effects [12]. Yet, Stegall et al. [13] recently demonstrated that Tac-based immunosuppression induces similar CNT lesions in the majority of patients and is responsible for substantial nonimmune-mediated nephrotoxicity after SOT. Since CNT is likely due to high peak levels of CNIs, researches have speculated that extended-release (ER) Tac drugs may reduce CNI-mediated toxicity in long-term exposure [14]. Currently, only limited research is available to support this hypothesis. In a small cross-over trial, Tremblay et al. [15] compared ER (Advagraf/Astagraf) and MeltDose formulations of Tac (LCPT-Tac or Envarsus). Tac ER is administrated once a day. Its absorption is slower than that of other Tac formulations; however, it provides the same exposure of Tac at the same dosage. MeltDose is a new technology with a higher bioavailability due to the usage of the small particle size. Reduced particle size enhances dissolution and absorption [14]. The ASTCOFF (all Tac formulation) study showed the highest Tac exposure for LCPT (Table 1) [15]. Studies have shown that CNI-induced tremor in transplanted patients was less observed in the LCPT-Envarsustreated group [15]. Both ER formulations are safe and effective in the prevention of kidney transplant rejection with noninferiority to immediate-release Tac for de novo kidney transplantation and secondary conversion [1618].

Given the narrow therapeutic window of CNIs, many investigators have attempted to introduce CNI-avoiding or CNI-withdrawing regimens in SOT, primarily by the substitution of CNI with the mammalian target of rapamycin (mTOR) inhibitors [19]. However, several large randomized studies showed an unacceptable high risk for early rejection after kidney transplantation in patients treated de novo with mTOR-inhibitor-based and CNIfree regimens (Table 1) [20-22]. Similarly, early or late conversion from CNI-containing regimens to mTOR inhibitors led to a surge in mild to moderate rejection events with increased risk for structural and sustained allograft damage (Table 1) [23-25]. Furthermore, high dose of mTOR inhibitor treatment was ill tolerated in many patients with treatment failure and reconversion to CNIs. Consequently, the hopes for CNI-free and purely mTORbased immunosuppression had to be abandoned as a treatment path for unselected kidney transplant recipients.

Therefore, in an alternative approach, reduced CNI exposure was tested in conjunction with mTOR inhibitors for de novo transplantation. In this landmark article, Pascual et al. [26] showed with the TRANSFORM trial in de novo transplanted patients that treatment with low-dose CNI combined with everolimus is noninferior to standard CNI (CsA or Tac) and mycophenolate mofetil treatment (Table 1). Allograft survival, achieved transplant function, incidence of de novo donor-specific antibodies, and acute antibody-mediated rejection (ABMR) were similar among the groups after 12 months of treatment. Intriguingly, the CNI + everolimus group showed significantly less infections than the CNI + mycophenolate mofetil group, notably cytomegalovirus (3.6 vs. 13.3\%) and polyomavirus 1 (BK virus) (4.3 vs. $8 \%$ ) [26]. Also, the 2 -year outcomes were among the 2 groups, meaning rejection rates and viral infections are low under combined treatment of CNI and everolimus [27].

While CNI seemed indispensable in kidney transplantation for decades, recent studies have promoted hope in novel CNI-avoiding regimens. Belatacept is an affinityand stability-engineered CTLA4-Fc (cytotoxic T-lymphocyte-associated protein 4) fusion protein and effectively blocks B7.1/B7.2-mediated costimulation in T cells [28]. In a first randomized trial, Vincenti et al. [29] showed that belatacept was noninferior compared with cyclosporine A for preventing acute kidney rejection. The BENEFIT (belatacept for kidney transplantation) and BENEFIT-EXT trials investigated belatacept compared to CNIbased immunosuppression in de novo kidney transplantation (Table 1) [30]. Overall outcome was excellent and belatacept-randomized patients showed superior kidney function as well as fewer chronic allograft nephropathy in the short- (1 year) [30] and long-term follow-up (7 years) [31]. However, early rejection and posttransplant lymphoproliferative disease were more frequent in the patient groups receiving belatacept $[30$, 
Table 1. Overview of clinical trials investigating CNI sparing and avoidance treatment in kidney transplanted patients

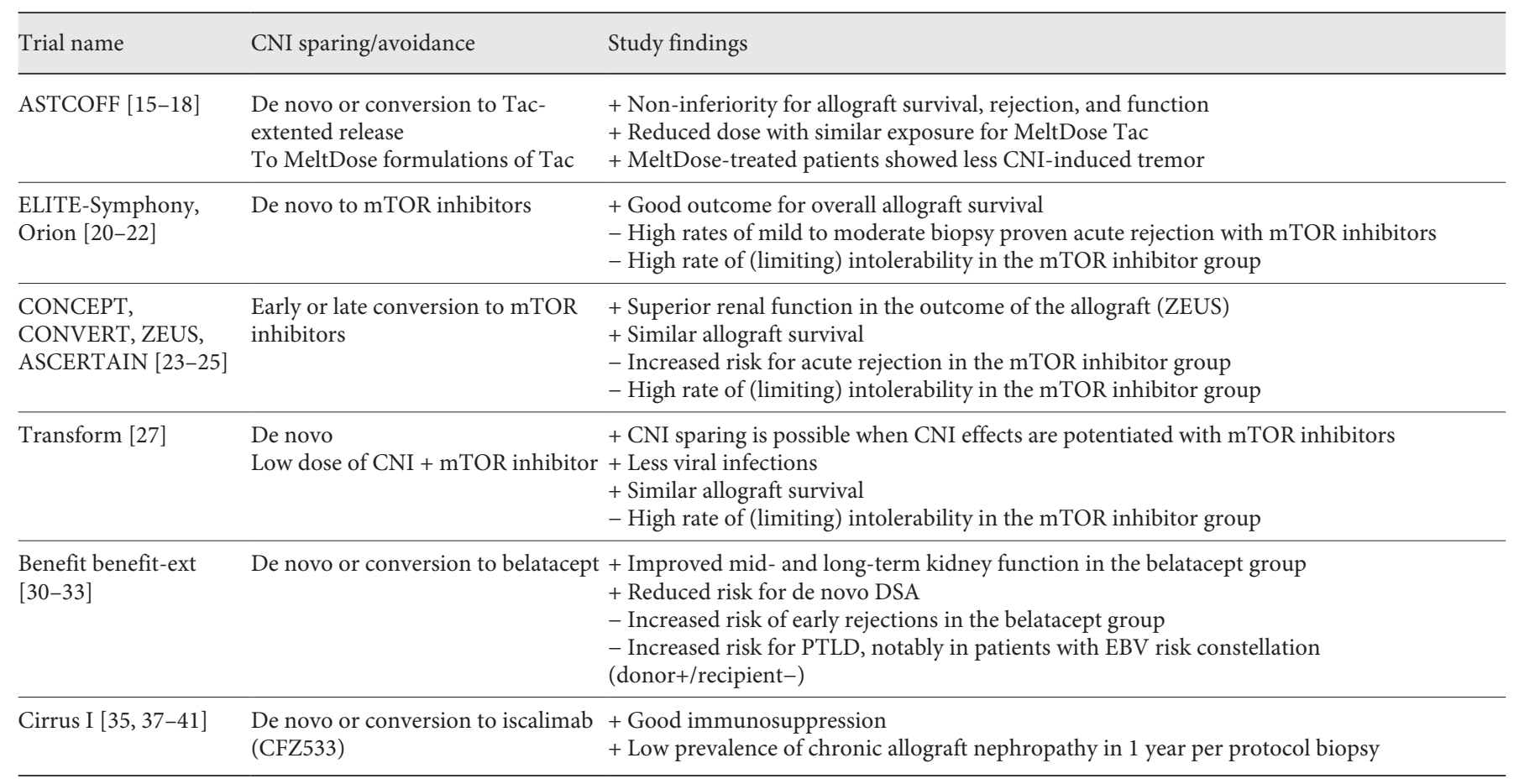

Tac, tacrolimus; DSA, donor-specific antibodies; PTLD, posttransplant lymphoproliferative disease; CNI, calcineurin inhibitor; mTOR, mammalian target of rapamycin.

32]. Due to the increased risk of developing posttransplant lymphoproliferative disease when under belatacept treatment, only EBV seropositive patients should be treated with belatacept.

Recently, monoclonal antibodies blocking CD40/ CD40L pathway have been evaluated in SOT [33]. CD40/ $\mathrm{CD} 40 \mathrm{~L}$ is the costimulatory signal needed to fully activate T-cells. It has been shown that blockage of the CD40L/ CD40 axis is effective to prevent allograft rejection and graft loss in nonhuman primate kidney transplantation [34]. Yet, antibodies directed against CD40L (CD154) increased the risk for thromboembolic events, which resulted in termination of clinical trials [35]. Meanwhile, blockage of CD40 with humanized nondepleting monoclonal antibodies, also known as iscalimab, showed to be safe in clinical phase I and II studies (Table 1) [36-40]. In 2019, first results from a phase II trial in kidney transplant patients under iscalimab treatment were demonstrated [36]. Currently, the Cirrus I trial studying the efficacy, safety, tolerability, and pharmacokinetic and dynamic properties of CD40 blockage in kidney transplantation is ongoing (NCT03663335, clinicaltrials.gov) [37].

Calcineurin Inhibitor Toxicity in Solid Organ Transplantation

\section{Histological Features/Transcriptomic Profiles}

Many debates have been held about the histological correlates of chronic CNT and their specificity. Longitudinal per-protocol biopsies in kidney transplant patients under CNI-containing regimens show progressive arterio- (ah) and arteriolohyalinosis (aah) (Table 2) (excentric hyaline matrix deposition in the small renal arteries) and IFTA [9]. Furthermore, severe and progressive ah/ aah and IFTA can be observed in allografts with active acute and chronic ABMR [41]. Furthermore, the degree of ah/aah lesions and IFTA seems not to correlate with the cumulative CNI dosage, although no detailed studies in this respect have been performed [42]. These lesions are not highly specific for CNI-induced changes since it was observed that kidneys from diseased donors are more prone to ah/aah lesions than kidneys from healthy donors [43]. Furthermore, other authors have suggested that predisposition to CNI nephrotoxicity is dependent on other donor- and recipient-derived factors, including genetic signatures and polymorphisms, since the histological and clinical presentation of CNT has shown high interindividual variations in patients (such as CYP $3 \mathrm{~A} 5^{*} 3 /{ }^{*} 3$ or TGF $\beta$ polymorphism in codon 10 ) with similar CNI reg- 
Table 2. Overview of the main characteristics of CNT in the kidney

\begin{tabular}{ll}
\hline Stage of CNT & Diagnostic criteria \\
\hline Acute CNT & \\
Hemodynamic effects & Vasoconstriction \\
Endothelial toxicity & TMA \\
Tubular toxicity & Tubular vacuolization \\
& Epithelial necrosis \\
& Loss of brush border \\
Chronic CNT & Arthero- and arteriohyalinosis \\
& Tubular atrophy \\
& Interstitial fibrosis (IFTA) \\
\hline
\end{tabular}

TMA, thrombotic microangiopathy; CNT, calcineurin inhibitor toxicity; IFTA, interstitial fibrosis and tubular atrophy.

imens $[44,45]$. That donor- and recipient-derived factors might influence ah/aah lesions was shown by Einecke who showed an independent association of ah/aah lesions with donor age and chronic glomerular disease independent of immunosuppression [46]. Similarly, uncontrolled hypertension, diabetes, recurrence of original disease, and other factors may influence predisposition to arteriohyalinosis.

To date, no serological or radiological marker to predict or measure CNT has been developed and validated. A method to assess rejection and injury in the transplanted kidney was developed by Halloran et al. The group developed the Molecular Microscope Diagnostic System, which is a microassay-based mRNA assessment. It is used in biopsies from transplants to assess the diagnosis, such as T-cell-mediated rejection and ABMR. Biopsies from kidney transplants are suitable to be evaluated by MMDx, as rejection of a kidney allograft is well characterized by histology and mRNA expression. The mRNA transcript change within the biopsies may represent the transcription change in cells [47]. To our knowledge, no study has investigated molecular signatures of kidney biopsies in patients with CNI-based and CNI-avoiding regimens (e.g., mTOR inhibitors, belatacept, and isaclimab) in patients with renal and nonrenal SOT.

\section{Hemodynamic Effects of Cyclosporine A}

Murray et al. [48] discovered that CsA treatment initiates vasoconstriction of the afferent arterioles [48, 49]. This constriction leads to a reduced diameter of the afferent arteriole, leading to less perfused kidneys (lower GFR) (Table 2). Furthermore, it has been shown that these vascular deteriorations occur due to CsA's activation of the renin angiotensin system (RAS). The RAS is activated when blood pressure is low, which induces a renin release. Renin cleaves from angiotensinogen the peptide angiotensin I, which is then converted to angiotensin II by the angiotensin-converting enzyme (ACE) $[50,51]$. But not only angiotensin II but also other mediators such as endothelin, which is increased in rat mesenteric artery after CsA treatment [52], and thromboxane [53] contribute to vasoconstriction. Moreover, CsA suppresses prostaglandin synthesis and the nitric oxide system, which acts as a vasodilator [54]. Therefore, much evidence points to the notion that CsA has a predominant functional effect on renal hemodynamic, comparable to ACE inhibitors or angiotensin-II-receptor antagonists (sartans), and that these compounds lead to a (partially reversible) deterioration of the eGFR $[55,56]$.

\section{Endothelial Toxicity}

Clearly, in certain circumstances, CNI can induce severe endothelial dysfunction with TMA and occlusion of the renal microvasculature during the early phase, 3-6 months, posttransplantation (Table 2). Unfortunately, half of the patients with TMA lose their renal allograft 2 years after TMA onset. Commonly, a dysregulation of the alternative complement pathway together with ABMR and/or high immunosuppressive treatment (CNI) is the underlying cause of TMA. The pathophysiology of CNIassociated TMA is incompletely understood, yet likely involves activation of prothrombotic factors due to $\mathrm{CNI}$ treatment and ischemia-reperfusion endothelial injury $[57,58]$. For around one-third of the patients, TMA can only be diagnosed in the renal allograft through biopsy as TMA manifests within the grafts without any hemolysis and thrombocytopenia. A promising treatment of TMA is discontinuation of CNI treatment and potentially plas$\mathrm{ma}$ and/or eculizumab, which inhibits the C5 protein of the complement system $[59,60]$.

\section{Tubular Toxicity}

Early experience with high doses of CNI demonstrated that acute CNI exposure may include nephrotoxicity with the histological correlation of tubular vacuolization and loss of brush borders. Such repeated events may have induced chronic CNT with tubulointerstitial fibrosis, arteriohyalinosis, and tubular atrophy (Table 2). Studies have shown that due to reduced diameter of the small vasculature, the renal parenchyma undergoes degenerative changes [61, 62]. Furthermore, these regions of the kidneys are more susceptible to injury due to their limited oxygen availability $[62,63]$. Reduced oxygen in the renal tissue promotes the development of chronic kidney dis- 


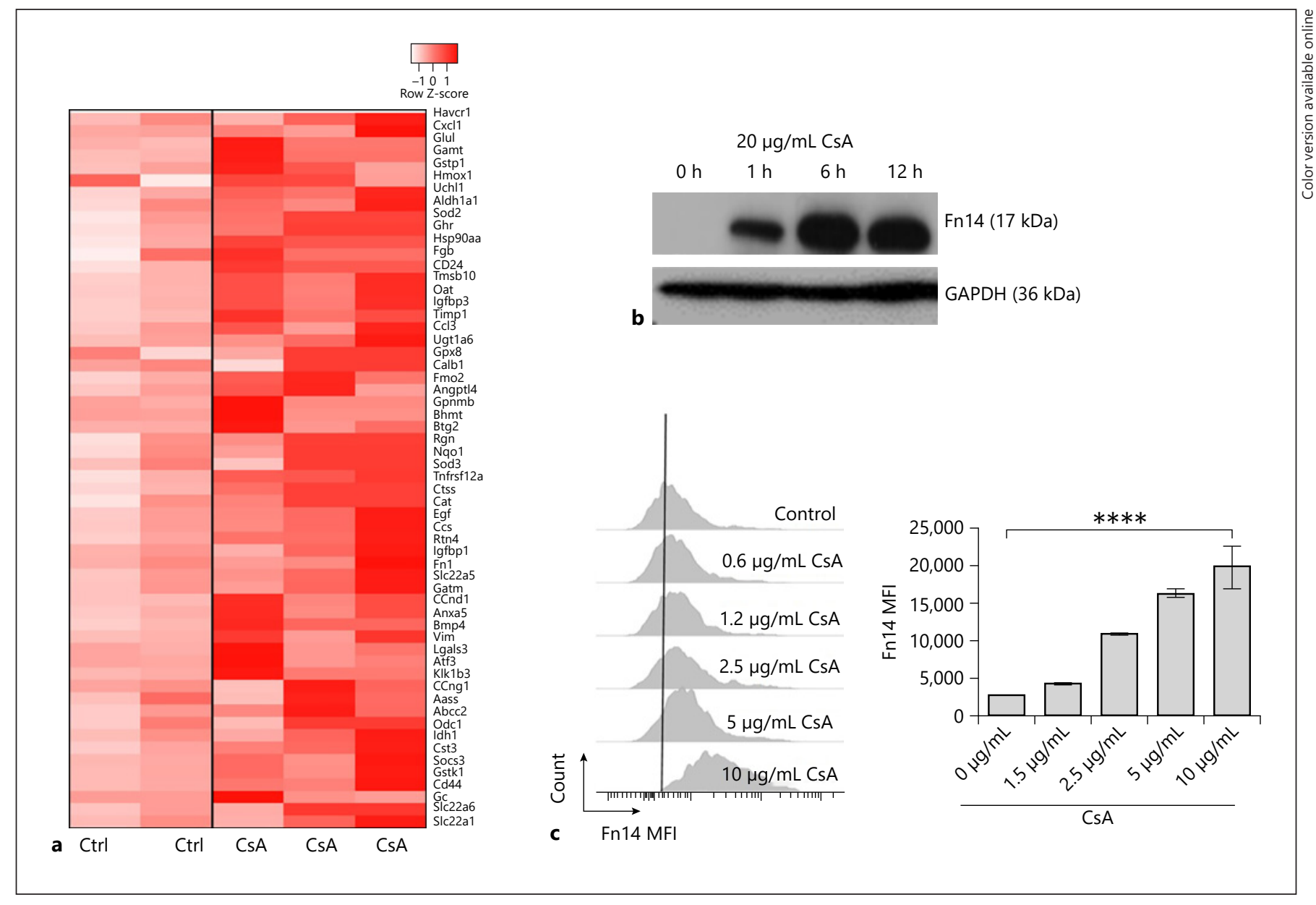

Fig. 1. CsA treatment induces pro-inflammatory and fibrotic signatures in vivo and in vitro. a Expression of selected genes involved in inflammation and fibrosis measured by RNA array (which 1) in kidneys after exposure of animals to $100 \mathrm{mg} / \mathrm{kg}$ CsA for 3 consecutive days. b Induction of Fn14 in total lysates and as c surface receptor expression on MCT treated with indicated concentrations of CsA (unpublished). CsA, cyclosporine A; MCT, murine tubular epithelial cells.

ease additionally to the nephrotoxicity induced by $\mathrm{CNI}$ treatment. Low oxygen leads to renal hypoxia and therefore also to ATP starvation. These will then activate fibrosis pathways. Interstitial fibrosis around the tubules in the kidney augments the diffusion distance between blood and tissue. Cippa showed that also patients with high domicile altitude show more progressive ah lesions than patients with lower residential altitude [64].

\section{Common Endpoints/Pathophysiology of CNT}

Repeated acute tubular toxicity and impaired renal hemodynamics induce vicious cycles of proinflammatory stress signals, such as cytokines, and effector molecules for tissue remodeling and fibrosis, including TGF $\beta$, IL4, and IL13 [65]. TGF $\beta 1$ is a cytokine involved in cell proliferation and cell differentiation as well as wound healing $[66,67]$. The cytokine is upregulated after tissue injury and contributes to tissue fibrosis development. Earlier studies showed that CsA treatment increases mRNA [68] as well as protein levels [69] of TGF $\beta 1$. Furthermore, TGF $\beta 1$ staining in kidney biopsies correlates with chronic changes in the vasculature and the kidney allograft outcome. Furthermore, TGF $\beta 1$ is a major stimulator for epithelial mesenchymal transition. Due to cytokine stimulus, epithelial cells start to express less epithelial specific markers but more fibroblast markers. Epithelial cells then differentiate into myofibroblasts [70, 71]. Indeed, we and others have demonstrated that exposure of mice to CsA 
induces a strong proinflammatory and profibrotic signature in the kidneys. In an in vivo model, mice (C57BL/6JRj) were treated with high dose of CsA $(100 \mathrm{mg} / \mathrm{kg})$. mRNA from the kidney was extracted and analyzed with a gene array for nephrotoxicity. The heatmap (Fig. 1a) showed significant upregulation of nephrotoxic genes involved in fibrosis and inflammation, including Fn14 (TNFRSF12A), vimentin, TIMP1, and CD44. Our group has recently elucidated the role of the TWEAK/Fn14 pathways in CNT. TWEAK (TNF-related weak inducer of apoptosis) is produced by myeloid cells and will bind to the surface receptor Fn14 (fibroblast growth factor-inducible 14) on epithelial cells. We could show that the protein Fn14 is time- (Fig. 1b) and dose-dependently (Fig. 1c) induced on kidney epithelial cells upon CsA treatment. The increase of the protein Fn14 was either measured by Western blot analysis (Fig. 1b) or the mean fluorescence intensity of Fn14 on the surface of the kidney epithelial cells using fluorescence-activated cell sorting (Fig. 1c) (unpublished). The binding of TWEAK to the Fn14 receptor will activate proinflammatory and profibrotic pathways that then contribute to CNT progression [72]. Furthermore, deficiency of TWEAK was sufficient to protect animals from acute CNT [73]. Fibrosis in the kidney leads to malfunctioning of the glomerulus, nephrons, and capillaries. Furthermore, the deposition of the extracellular matrix will further stimulate immune cells that are secreting more cytokines and therefore contributing further to inflammation [74]. That kind of inflammatory environment imposed by alloreactivity immunity promotes a more aggressive CNT. Inflammation and fibrosis in the kidney decrease the survival of the transplanted kidney allograft.

\section{Treatment}

Currently, no specific treatments to prevent, halt, or reverse CNT are available. Research in this field is limited, mainly due to the fact that modeling chronic CNT is cumbersome in experimental animals. Inbred mice show a high resistance toward chronic CNI-induced kidney lesions, even when treated at (supra)maximal doses and for prolonged time frames. The reason for this is unknown, but is likely due to high renal reserves. This reserve gives the kidney the possibility to adapt to stress stimuli and therefore increase the eGFR [75]. Furthermore, inbred mice (such as C75BL/6) have only 1 renin gene and therefore less activation of the RAS, which essentially would lead to less vasoconstriction [76]. Conversely, inbred rats (WISTAR) develop arteriohyalinosis, but long treatment regimens with repeated injections or osmotic pumps are needed.
Several approaches have been conducted to ameliorate CNT. Andoh et al. [77] showed that severe salt restriction may accelerate CNT in rats. Rats treated with CsA and on a low salt diet developed features of chronic nephrotoxicity compared with rats receiving the same dose of CsA but standard salt diet. Then CsA treatment was stopped, and all groups received high salt diets. Interestingly, only rats that developed prior CNT showed an increase in blood pressure. However, the mechanisms of disease are unclear. It is possible that salt restriction induces intrarenal fibrotic loops. Alternatively, it is possible that the profibrotic effect is related to decreased blood pressure, hemodynamic-mediated deterioration of renal perfusion, and subsequent induction of chronic inflammation and fibrosis [77].

Other authors have suggested that CNT can be alleviated by dietary potassium and magnesium supplementation. An in vivo study with rats investigated if supplementation of potassium or magnesium would ameliorate CsA-induced hypertension and nephrotoxicity. Both dietary supplementation showed a decrease of CNT. However, magnesium supplementation was much more beneficial against CNT than potassium supplementation. Interestingly, the combination of potassium and magnesium showed the best protection against CNT [78]. The beneficial effect of potassium supplementation is due to natriuresis and less sodium-induced elevation of blood pressure [79]. Other studies have shown that magnesium induces vasodilatation in arteries and therefore serves as a protection against CNT $[80,81]$.

It was shown that $\mathrm{Ca}^{2+}$ channel blockers prevent CsAassociated hypertension [82] as well as renal hypoperfusion, meaning there is a decrease in renal blood flow [83]. Early on, it was shown that lacidipine (a calcium channel blocker) prevents the decrease in GFR in renal allografts when administrated additionally to CsA. It was observed that GFR decreased as soon as lacidipine was discontinued [83]. Recently, a retrospective study (FAVORIT, NCT00064753) evaluating the benefit of calcium channel blocking agents after renal transplantation was performed. In this analysis, it was found that calcium channel blockers did not significantly increase the survival of the kidney allograft [84]. Strikingly, the same results were shown in another clinical trial with 210 patients with renal allografts. However, this study showed that overall the group receiving calcium channel blockers had a significantly better renal function [85]. Conclusively, administration of $\mathrm{Ca}^{2+}$ channel blockers with $\mathrm{CNI}$ ameliorates the renal function but not the overall survival of the renal allograft. 
Finally, others have suggested that the combined effect of CNI and blockers of the RAS may ameliorate CNT in transplanted patients. First, it was shown that patients with chronic kidney disease show a slower loss of kidney function when under ACE inhibitors. It has been shown that ACE inhibitor administration in rats improves the survival of the transplanted allograft. The treatment showed lower systemic and glomerular capillary pressure. On the histological level, it was observed that ACE inhibitors prevented atherosclerosis development [86].

Other potential drugs minimizing the toxicity of $\mathrm{CNI}$ on the renal allograft are mineralocorticoid receptor antagonists such as aldosterone inhibitors (eplerenone and spironolactone). Rats receiving in addition to CsA treatment aldosterone inhibitors showed less arteriolopathy and less tubulointerstitial fibrosis [87]. The SPIREN trial evaluated the effect of spironolactone in patients with renal allograft. It could be shown that administration of a mineralocorticoid receptor antagonism is beneficial for the renal allograft outcome (fibrosis) and survival (NCT01021943) [88].

\section{Conclusion}

Clinical and subclinical toxicity of CNIs is almost uniformly dominant in solid organ transplant recipients. Notably, progressive nonimmune-mediated deterioration of kidney function is common. Clearly, the predisposition to develop clinically relevant $\mathrm{CNT}$ is highly variable and may depend on comedication, comorbidity, and genetic predisposition. Currently, the precise mechanisms of action for CNT development are not known, neither for kidney disease nor extra-renal disease. To date, no measures to prevent, alleviate, or revert CNT are known. Given the notion that CNIs remain a dominant pillar of immunosuppressive regimens in renal and nonrenal transplanted patients, CNT will remain a critical momentum for severe morbidity within the SOT community. For the future, either novel immunosuppressive therapy which allows CNI avoidance or protective/preemptive or therapeutic measures to cope with CNT are needed.

\section{Statement of Ethics}

This study protocol was reviewed and approved by the Veterinärdienst of the Canton BE, Sekretariat Tierversuche (approval number BE63/19).

\section{Conflict of Interest Statement}

The authors have no conflicts of interest to declare.

\section{Funding Sources}

After discussion with Prof. Vogt, we can declare that this work was funded through institutional funds for Daniel Sidler.

\section{Author Contributions}

Andrea Karolin: wrote the paper and performed the literature search. Vera Genitsch: wrote the paper and discussed the literature search. Daniel Sidler: established the layout, performed the literature search, and wrote the paper.

\section{References}

1 Taylor DO, Barr ML, Radovancevic B, Renlund DG, Mentzer RM, Smart FW, et al. A randomized, multicenter comparison of tacrolimus and cyclosporine immunosuppressive regimens in cardiac transplantation: decreased hyperlipidemia and hypertension with tacrolimus. J Heart Lung Transplant. 1999 Apr 1;18(4):336-45.

2 Keogh A. Calcineurin inhibitors in heart transplantation. J. Heart Lung Transplant. 2004 May 1;23(5):S202-6.

3 Hume DM, Merrill JP, Miller BF, Thorn GW. Experiences with renal homotransplantation in the human: report of nine cases. J Clin Invest. 1955;34(2):327-82.

4 Tanaka H. Serological typing of HLA. Rinsho byori. JPN J Clin Oncol. 1999.
5 Casey MJ, Meier-Kriesche H-U. Calcineurin inhibitors in kidney transplantation: friend or foe? Curr Opin Nephrol Hypertens. 2011.

6 Magnone M. Expanding the kidney allograft donor pool in the tacrolimus era. Surg Technol Int. 1995;IV:301-3

7 Stein DP, Lederman RJ, Vogt DP, Carey WD Broughan T. Neurological complications following liver transplantation. Ann Neurol. 1992;31(6):644-9.

8 Myers BD, Ross J, Newton L, Luetscher J, Perlroth $\mathrm{M}$. Cyclosporine-associated chronic nephropathy. N Engl J Med. 1984;311(11):699-705.

9 Nankivell BJ, Borrows RJ, Fung CLS, O'Connell PJ, Allen RDM, Chapman JR. The natural history of chronic allograft nephropathy. N Engl J Med. 2003;349(24):2326-33.
10 Ojo AO, Held PJ, Port FK, Wolfe RA, Leichtman AB, Young EW, et al. Chronic renal failure after transplantation of a nonrenal organ. N Engl J Med. 2003;349(10):931-40.

11 Marcén R, Morales JM, Fernández-Rodriguez A, Capdevila L, Pallardó L, Plaza JJ, et al. Long-term graft function changes in kidney transplant recipients. NDT Plus. 2010;3(Suppl 2):ii2.

12 Ekberg H, Tedesco-Silva H, Demirbas A, Vítko Š, Nashan B, Gürkan A, et al. Reduced exposure to calcineurin inhibitors in renal transplantation. N Engl J Med. 2007 Dec 20; 357(25):2562-75. 
13 Stegall MD, Cornell LD, Park WD, Smith BH, Cosio FG. Renal allograft histology at 10 years after transplantation in the tacrolimus era: evidence of pervasive chronic injury. Am J Transplant. 2018;18(1):180-8.

14 Baraldo M. Meltdose tacrolimus pharmacokinetics. Transplant Proc. 2016;48(2):420.

15 Tremblay S, Nigro V, Weinberg J, Woodle ES, Alloway RR. A steady-state head-to-head pharmacokinetic comparison of all fk-506 (tacrolimus) formulations (ASTCOFF): an open-label, prospective, randomized, twoarm, three-period crossover study. Am J Transplant. 2017;17(2):432-42.

16 Budde K, Bunnapradist S, Grinyo JM, Ciechanowski K, Denny JE, Silva HT, et al. Novel once-daily extended-release tacrolimus (LCPT) versus twice-daily tacrolimus in de novo kidney transplants: one-year results of phase III, double-blind, randomized trial. Am J Transplant. 2014;14(12):2796-806.

17 Bunnapradist S, Ciechanowski K, West-Thielke P, Mulgaonkar S, Rostaing L, Vasudev B, et al. Conversion from twice-daily tacrolimus to once-daily extended release tacrolimus (LCPT): the phase III randomized MELT trial. Am J Transplant. 2013;13(3):760-9.

18 Slatinska J, Rohal T, Wohlfahrtova $M$ Viklicky O. Long-term follow-up of stable kidney transplant recipients after conversion from tacrolimus twice daily immediate release to tacrolimus once-daily prolonged release: a large single-center experience. Transplant Proc. 2013;45(4):1491-6.

19 Tedesco Silva $\mathrm{H}$. The long journey of mtor inhibitors and the long path that is still ahead. Transplantation. 2018 Feb 1;102(Suppl 1): S1-2.

20 Ekberg H, Tedesco-Silva H, Demirbas A, Vítko Š, Nashan B, Gürkan A, et al. Reduced exposure to calcineurin inhibitors in renal transplantation. N Engl J Med. 2007 Dec 20; 357(25):2562-75.

21 Flechner SM, Glyda M, Cockfield S, Grinyõ J, Legendre C, Russ G, et al. The orion study: comparison of two sirolimus-based regimens versus tacrolimus and mycophenolate mofetil in renal allograft recipients. Am J Transplant. 2011.

22 Flechner SM, Gurkan A, Hartmann A, Legendre CM, Russ GR, Campistol JM, et al. A randomized, open-label study of sirolimus versus cyclosporine in primary de novo renal allograft recipients. Transplantation. 2013.

23 Lebranchu Y, Thierry A, Toupance O, Westeel PF, Etienne I, Thervet E, et al. Efficacy on renal function of early conversion from cyclosporine to sirolimus 3 months after renal transplantation: concept study. Am J Transplant. 2009.

24 Schena FP, Pascoe MD, Alberu J, Del Carmen Rial M, Oberbauer R, Brennan DC, et al. Conversion from calcineurin inhibitors to sirolimus maintenance therapy in renal allograft recipients: 24-month efficacy and safety results from the CONVERT trial. Transplantation. 2009.
25 Holdaas H, Rostaing L, Serón D, Cole E, Chapman J, Fellstrøm B, et al. Conversion of long-term kidney transplant recipients from calcineurin inhibitor therapy to everolimus: a randomized, multicenter, 24-month study. Transplantation. 2011.

26 Pascual J, Berger SP, Witzke O, Tedesco H, Mulgaonkar S, Qazi Y, et al. Everolimus with reduced calcineurin inhibitor exposure in renal transplantation. J Am Soc Nephrol. 2018.

27 Berger SP, Sommerer C, Witzke O, Tedesco $\mathrm{H}$, Chadban S, Mulgaonkar S, et al. Two-year outcomes in de novo renal transplant recipients receiving everolimus-facilitated calcineurin inhibitor reduction regimen from the TRANSFORM study. Am J Transplant. 2019.

28 Larsen CP, Pearson TC, Adams AB, Tso P, Shirasugi $\mathrm{N}$, Strobert E, et al. Rational development of LEA29Y (belatacept), a high-affinity variant of CTLA4-Ig with potent immunosuppressive properties. Am J Transplant. 2005.

29 Vincenti F, Larsen C, Durrbach A, Wekerle T, Nashan B, Blancho G, et al. Costimulation Blockade with Belatacept in Renal Transplantation. N Engl J Med. 2005 Aug 25;353(8): 770-81.

30 Vincenti F, Charpentier B, Vanrenterghem Y, Rostaing L, Bresnahan B, Darji P, et al. A phase III study of belatacept-based immunosuppression regimens versus cyclosporine in renal transplant recipients (BENEFIT Study). Am J Transplant. 2010;10(3):535.

31 Vincenti F, Rostaing L, Grinyo J, Rice K, Steinberg S, Gaite L, et al. Belatacept and longterm outcomes in kidney transplantation. N Engl J Med. 2016;374(4):333.

32 Durrbach A, Pestana JM, Pearson T, Vincenti F, Garcia VD, Campistol J, et al. A phase III study of belatacept versus cyclosporine in kidney transplants from extended criteria donors (BENEFIT-EXT Study). Am J Transplant. 2010 Mar;10(3):547-57.

33 Wojciechowski D, Vincenti F. Current status of costimulatory blockade in renal transplantation. Curr Opin Nephrol Hypertens. 2016; 25(6):583

34 Cordoba F, Wieczorek G, Audet M, Roth L, Schneider MA, Kunkler A, et al. A novel, blocking, Fc-silent anti-CD40 monoclonal antibody prolongs nonhuman primate renal allograft survival in the absence of B cell depletion. Am J Transplant. 2015;15(11):2825.

35 Vincenti F. New monoclonal antibodies in renal transplantation. Minerva Urol Nefrol. 2003;55(1):57.

36 Nashan B, Tedesco H, Van Den Hoogen M, Berger S, Cibrik D, Mulgaonkar S, et al. CFZ533, a new anti-CD40 mab demonstrates comparable efficacy and better renal function versus tacrolimus in de-novo CNI-free kidney transplantation. Am J Transplant. 2018.

37 Espié P, He Y, Koo P, Sickert D, Dupuy C, Chokoté E, et al. First-in-human clinical trial to assess pharmacokinetics, pharmacodynamics, safety, and tolerability of iscalimab, an anti-CD40 monoclonal antibody. Am J Transplant. 2020 Feb 6;20(2):463-73.
38 Albach FN, Wagner F, Hüser A, Igel J, Joseph D, Hilbert J, et al. Safety, pharmacokinetics and pharmacodynamics of single rising doses of BI 655064, an antagonistic antiCD40 antibody in healthy subjects: a potential novel treatment for autoimmune diseases. Eur J Clin Pharmacol. 2018;74(2): 161-9.

39 Goldwater R, Keirns J, Blahunka P, First R, Sawamoto T, Zhang W, et al. A phase 1, randomized ascending single-dose study of antagonist anti-human CD40 ASKP1240 in healthy subjects. Am J Transplant. 2013; 13(4): 1040

40 Ristov J, Espie P, Ulrich P, Sickert D, Flandre $\mathrm{T}$, Dimitrova M, et al. Characterization of the in vitro and in vivo properties of CFZ533, a blocking and non-depleting anti-CD40 monoclonal antibody. Am J Transplant. 2018; 18(12):2895.

41 Haas M. The relationship between pathologic lesions of active and chronic antibody-mediated rejection in renal allografts. Am J Transplant. 2018;18(12):2849.

42 Myers BD, Newton L. Cyclosporine-induced chronic nephropathy: an obliterative microvascular renal injury. J Am Soc Nephrol. 1991; 2(2 Suppl 1):S45.

43 Mohan S, Campenot E, Chiles MC, Santoriello D, Bland E, Crew RJ, et al. Association between reperfusion renal allograft biopsy findings and transplant outcomes. J Am Soc Nephrol. 2017;28(10):3109.

44 Baan CC, Balk AHMM, Holweg CTJ, Van Riemsdijk IC, Maat LPWM, Vantrimpont PJMJ, et al. Renal failure after clinical heart transplantation is associated with the TGF- $\beta 1$ codon 10 gene polymorphism. J Hear Lung Transplant. 2000;23(2):171.

45 Xia T, Zhu S, Wen Y, Gao S, Li M, Tao X, et al. Risk factors for calcineurin inhibitor nephrotoxicity after renal transplantation: a systematic review and meta-analysis. Drug Des Devel Ther. 2018;12:417.

46 Einecke G, Reeve J, Halloran PF. Hyalinosis lesions in renal transplant biopsies: time-dependent complexity of interpretation. Am J Transplant. 2017 May 1;17(5):1346-57.

47 Halloran PF, Reeve J, Akalin E, Aubert O, Bohmig GA, Brennan D, et al. Real time central assessment of kidney transplant indication biopsies by microarrays: the INTERCOMEX study. Am J Transplant. 2017;17(11): 2851.

48 Murray BM, Paller MS, Ferris TF. Effect of cyclosporine administration on renal hemodynamics in conscious rats. Kidney Int. 1985; 28(5):767-74

49 Dieperink H, Starklint H, Leyssac PP. Nephrotoxicity of cyclosporine. An animal model: study of the nephrotoxic effect of cyclosporine on overall renal and tubular function in conscious rats. Transplant Proc. 1983.

50 Olyaei AJ, De Mattos AM, Bennett WM Nephrotoxicity of immunosuppressive drugs: new insight and preventive strategies. Curr Opin Crit Care. 2001;7(6):384 
51 Burdmann EA, Andoh TF, Yu L, Bennett WM. Cyclosporine nephrotoxicity. Semin Nephrol. 2003;23(5):465-76.

52 Takeda Y, Miyamori I, Wu P, Yoneda T, Furukawa $\mathrm{K}$, Takeda $\mathrm{R}$. Effects of an endothelin receptor antagonist in rats with cyclosporineinduced hypertension. Hypertension. 1995.

53 Cediel E, va zquez-Cruz B, Navarro-Cid J, De N, Heras L, Sanz-Rosa D, et al. Role of endothelin-1 and thromboxane A 2 in renal vasoconstriction induced by angiotensin II in diabetes and hypertension. Kidney Int Suppl. 2002.

54 Oriji GK, Keiser HR. Nitric oxide in cyclosporine A-induced hypertension: role of protein kinase C. Am J Hypertens. 1999.

55 Guidi E, Minetti EE, Cozzi MG. Acute and long-term effects of ACE inhibition on renal haemodynamics in glomerular and interstitial nephropathies. J Renin Angiotensin Aldosterone Syst. 2002;3(1):40.

56 Wu Z, Zhang H, Jin W, Liu Y, Lu L, Chen Q, et al. The effect of renin-angiotensin-aldosterone system blockade medications on contrast- induced nephropathy in patients undergoing coronary angiography: a meta-analysis. PLoS One. 2015.

57 Franz M, Regele H, Schmaldienst S, Stummvoll HK, Hörl WH, Pohanka E. Postransplant hemolytic uremic syndrome in adult retransplanted kidney graft recipients. Advantage of FK506 therapy. Transplantation. 1998.

58 Noris M, Remuzzi G. Thrombotic microangiopathy after kidney transplantation. Am J Transplant. 2010;10(7):1517.

59 Yango A, Morrissey P, Monaco A, Butera J, Gohh RY. Successful treatment of tacrolimusassociated thrombotic microangiopathy with sirolimus conversion and plasma exchange [1]. Clin Nephrol. 2002;58(1):77.

60 Abbas F, Kossi E, Kim JJ, Sharma A, Halawa A. Thrombotic microangiopathy after renal transplantation: Current insights in de novo and recurrent disease. World J Transplant. 2018;8(5):122-41.

61 Randhawa PS, Starzl TE, Demetris AJ. Tacrolimus (FK506)-Associated Renal Pathology. Adv Anat Pathol. 1997;4(4):265-76.

62 Stillman IE, Brezis M, Heyman SN, Epstein FH, Spokes K, Rosen S. Effects of salt depletion on the kidney: changes in medullary oxygenation and thick ascending limb size. J Am Soc Nephrol. 1994;4(8): 1538.

63 Rosen S, Greenfeld Z, Brezis M. Chronic cyclosporine-induced nephropathy in the rat: a medullary ray inner stripe injury. Transplantation. 1990;49(2):445-52.
64 Cippà $\mathrm{PE}$, Grebe SO, Fehr T, Wüthrich RP, Mueller TF. Altitude and arteriolar hyalinosis after kidney transplantation. Nephrology. 2016.

65 Fertin C, Nicolas JF, Gillery P, Kalis B, Banchereau J, Maquart FX. Interleukin-4 stimulates collagen synthesis by normal and scleroderma fibroblasts in dermal equivalents. Cell Mol Biol. 1991.

66 Pohlers D, Brenmoehl J, Löffler I, Müller CK, Leipner C, Schultze-Mosgau S, et al. TGF- $\beta$ and fibrosis in different organs - molecular pathway imprints. Biochim Biophys Acta. 2009;1792(8):746.

67 Faler BJ, Macsata RA, Plummer D, Mishra L, Sidawy AN. Transforming growth factor- $\beta$ and wound healing. Perspect Vasc Surg Endovasc Ther. 2006.

68 Shin GT, Khanna A, Sharma VK, Ding R, Azizlerli $\mathrm{S}, \mathrm{Li} \mathrm{B}$, et al. In vivo hyperexpression of transforming growth factor- $\beta 1$ in humans: stimulation by cyclosporine. Transplant Proceedings. 1997.

69 Mohamed MAS, Robertson H, Booth TA, Balupuri S, Kirby JA, Talbot D. TGF- $\beta$ expression in renal transplant biopsies: a comparative study between cyclosporin-A and tacrolimus. Transplantation. 2000.

70 Kalluri R, Neilson EG. Epithelial-mesenchymal transition and its implications for fibrosis. Clin Invest. 2003;112(12):1776.

71 Baczkowska T, Perkowska-Ptasińska A, Lewandowski Z, Nowacka-Cieciura E, Cieciura T, Pazik J, et al. Serum TGF- $\beta 1$ correlates with chronic histopathological lesiones in protocol biopsies in kidney allograft recipients. Transplantation. 2004.

72 Burkly LC. TWEAK/Fn14 axis: the current paradigm of tissue injury-inducible function in the midst of complexities. Semin Immunol. 2014;26(3):229.

73 Claus M, Herro R, Wolf D, Buscher K, Rudloff $S$, Huynh-Do U, et al. The TWEAK/Fn14 pathway is required for calcineurin inhibitor toxicity of the kidneys. Am J Transplant. 2018;18(7):1636

74 Portilla D. Apoptosis, fibrosis and senescence. Neph Clin Prac. 2014.

75 Thomas DM, Coles GA, Williams JD. What does the renal reserve mean? Kidney Int. 1994.

76 Rabe M, Schaefer F. Non-transgenic mouse models of kidney disease. Nephron. 2016 Jun 1;133(1):53-61.

77 Andoh TF, Johnson RJ, Lam T, Bennett WM. Subclinical renal injury induced by transient cyclosporine exposure is associated with saltsensitive hypertension. Am J Transplant. 2001 Sep 1;1(3):222-7.
78 Pere AK, Lindgren L, Tuomainen P, Krogerus L, Rauhala P, Laakso J, et al. Dietary potassium and magnesium supplementation in cyclosporine-induced hypertension and nephrotoxicity. Kidney Int. 2000.

79 Fujita T, Ando K. Hemodynamic and endocrine changes associated with potassium supplementation in sodium-loaded hypertensives. Hypertension. 1984.

80 Nagai I, Gebrewold A, Altura BT, Altura BM. Magnesium salts exert direct vasodilator effects on rat cremaster muscle microcirculation. Arch Int Pharmacodyn Ther. 1988.

81 Nishio A, Grebrewold A, Altura BT, Altura BM. Comparative vasodilator effects of magnesium salts on rat mesenteric arterioles and venules. Arch Int Pharmacodyn Ther. 1989.

82 Kirk AJB, Omar I, Dark JH. Long-term improvement in renal function using nifedipine in cyclosporine-associated hypertension. Transplantation [Internet]. 1990;50(6):1061.

83 Ruggenenti P, Perico N, Mosconi L, Gaspari F, Benigni A, Amuchastegui CS, et al. Calcium channel blockers protect transplant patients from cyclosporine-induced daily renal hypoperfusion. Kidney Int. 1993;43(3):706-11.

84 Weinrauch LA, Liu J, Claggett B, Finn PV, Weir MR, D’Elia JA. Calcium channel blockade and survival in recipients of successful renal transplant: An analysis of the FAVORIT trial results. Int J Nephrol Renovasc Dis. 2018; 11:1-7.

85 van Riemsdijk IC, Mulder PG, de Fijter JW, Bruijn JA, van Hooff JP, Hoitsma AJ, et al. Addition of isradipine (Lomir) results in a better renal function after kidney transplantation: a double-blind, randomized, placebo-controlled, multi-center study. Transplantation. 2000 Jul 15;70(1):122-6.

86 Paul M, Ganten D. The molecular basis of cardiovascular hypertrophy: the role of the renin-angiotensin system. J Cardiovasc Pharmacol. 1992.

87 Thomsen Nielsen F, Jensen BL, Marcussen N, Skøtt O, Bie P. Inhibition of mineralocorticoid receptors with eplerenone alleviates short-term cyclosporin A nephrotoxicity in conscious rats. Nephrol Dial Transplant. 2008;23:2777-83.

88 Mortensen LA, Thiesson HC, Tougaard B, Egfjord M, Fischer ASL, Bistrup C. The effect of spironolactone on calcineurin inhibitor induced nephrotoxicity: a multicenter randomized, double-blind, clinical trial (the SPIREN trial). BMC Nephrol. 2018 May 3;19(1):105. 